\title{
Curcumin suppresses colorectal tumorigenesis via the Wnt/及-catenin signaling pathway by downregulating Axin2
}

\author{
JIAXUE HAO ${ }^{1}$, XUFEN DAI $^{2}$, JUAN GAO $^{1}$, YUEXUAN LI ${ }^{1}$, \\ ZHAOLING HOU $^{1}$, ZHONGMAN CHANG ${ }^{1}$ and YUXIN WANG ${ }^{1}$
}

${ }^{1}$ Key Laboratory of Resource Biology and Biotechnology in Western China, Ministry of Education/College of Life Science,
Northwest University, Xi'an, Shaanxi 710069; ${ }^{2}$ Food and Drug Technology Research Center, Shaanxi Province Food and
Drug Supervision and Inspection Research, Shaanxi Institute for Food and Drug Control, Xi'an, Shaanxi 710065, P.R. China

Received June 24, 2020; Accepted November 20, 2020

DOI: $10.3892 / 01.2021 .12447$

\begin{abstract}
Colorectal cancer (CRC) is the third most common cancer worldwide, with high incidence and mortality rates. Conventional therapies, including surgery, chemotherapy and radiation, are extensively used for the treatment of CRC. However, patients present with adverse effects, such as toxicity, hepatic injury and drug resistance. Thus, there is an urgent requirement to identify effective and safe therapy for CRC. Curcumin (CUR), a polyphenol substrate extracted from the rhizome of Curcuma longa, has been extensively studied for the treatment of CRC due to its high efficacy and fewer side effects. Previous studies have reported that several signaling pathways, such as NF- $\kappa \mathrm{B}, \mathrm{Wnt} / \beta$-catenin, are involved in the antitumor effects of CUR in vitro. However, the effect and mechanisms in vivo are not yet fully understood. The present study aimed to determine the molecular mechanism of colorectal cancer in vivo. Reverse transcription-quantitative PCR, western blot and immunohistochemistry analyses were performed to determine the underlying molecular mechanism of curcumin's anti-cancer effect in azoxymethane-dextran sodium sulfate induced colorectal cancer. The results of the present study demonstrated that CUR suppressed tumorigenesis in AOM-DSS induced CRC in mice, and anticancer effects were exerted by suppressing the expression of pro-inflammatory cytokines, and downregulating Axin2 in the Wnt/ $\beta$-catenin signaling pathway. Taken together, these results
\end{abstract}

Correspondence to: Dr Yuxin Wang, Key Laboratory of Resource Biology and Biotechnology in Western China, Ministry of Education/College of Life Science, 229 Northwest University, Xi'an, Shaanxi 710069, P.R. China

E-mail: yuxinwang1988@gmail.com

Abbreviations: AOM-DSS, azoxymethane-dextran sodium sulfate; CUR, curcumin; CRC, colorectal cancer; IL, interleukin; H\&E, hematoxylin and eosin

Key words: curcumin, colorectal cancer, mechanism, Wnt/ß-catenin, Axin2 exhibit the potential in vivo mechanisms of the anticancer effects of CUR, and highlight Axin2 as a potential therapeutic target for CRC.

\section{Introduction}

Colorectal cancer (CRC) is a leading cause of mortality worldwide (1), and it has been estimated that the morbidity and mortality of CRC are increasing rapidly, with nearly 1.2 million new patients and 600,000 mortalities annually (2). CRC treatment including surgery, chemotherapy and radiation are commonly used; however, patients suffer severe side effects following these therapies, such as toxicity, hepatic injury and drug resistance $(3,4)$. Thus, it remains urgent to identify novel therapies for $\mathrm{CRC}$, with high efficacy and fewer adverse effects.

Curcumin (CUR), a natural product extracted from the rhizome of Curcuma longa (5), is a drug with strong pharmacological effects and limited side effects $(6,7)$. Increasing evidence have confirmed that CUR exerts antioxidant, antibacterial, anti-inflammatory, antiproliferation and anticancer effects (8-11). Furthermore, curcuminoids have been approved by the US Food and Drug Administration (FDA) as 'Generally Recognized As Safe' (GRAS) (12), and clinical trials have demonstrated good tolerability and safety profiles, at doses between 4,000-8,000 mg/day $(12,13)$. In another phase I clinical trial, CUR (at doses 0.45-3.6 g) was administered to 15 patients with advanced CRC who were resistant to chemotherapy for 4 months. The results demonstrated that treatment with CUR was well tolerated and there was no toxicity at any doses (14).

Previous studies have reported several molecular mechanisms for the anticancer effects of CUR. For example, CUR inhibits Axin2 expression in the colorectal cancer line, HCT116, and modulates the Wnt/ $\beta$-catenin signaling pathway (15). Yan et al (16) demonstrated that Axin2 is upregulated and the $\mathrm{Wnt} / \beta$-catenin signaling pathway is activated in human colon tumor samples. It has also been reported that CUR can target colorectal stem cells via the Wnt pathway to inhibit their proliferation and drug resistance to chemotherapy (14), indicating the important role of the $\mathrm{Wnt} / \beta$-catenin signaling pathway in the tumorigenesis of CRC. Another study 
demonstrated that CUR inhibits the proliferation and induces apoptosis of human non-small cell lung cancer cells via the PI3K/Akt signaling pathway (17). Furthermore, the results of a squamous cell carcinoma study reported that CUR inhibits cancer cell proliferation via the epidermal growth factor receptor signaling pathway (18). In addition to the effects of CUR on CRC progression through the NBR2/AMPK/mTOR pathway (19), CUR regulates the $\mathrm{NF}-\kappa \mathrm{B}$ and Src protein kinase signaling pathways by inhibiting $\mathrm{I} \kappa \mathrm{B} \alpha$ kinase activation and $\mathrm{I} \kappa \mathrm{B} \alpha$ phosphorylation (20). Collectively, these results indicate several molecular mechanisms of the anticancer effects of CUR in vitro. However, the in vivo mechanism remains to be elucidated. Thus, the present study aimed to investigate the anticancer effects of CUR and determine its underlying mechanisms in CRC, in vivo.

The results of the present study demonstrated that CUR abrogated CRC induced by azoxymethane (AOM)-dextran sodium sulfate (DSS). In addition, reverse transcription-quantitative (RT-q)PCR, western blot and immunohistochemistry (IHC) analysis demonstrated that CUR attenuated CRC by downregulating Axin2 expression, which is a key downstream target in the Wnt/ $\beta$-catenin signaling pathway (14), and decreasing the expression of pro-inflammatory cytokines. Taken together, these results demonstrate the mechanisms of the anticancer effects of CUR in vivo, and suggest that Axin2 may act as a potential therapeutic target for CRC.

\section{Materials and methods}

Reagents and chemicals. AOM (cat. no. SLBX6213) was purchased from Sigma-Aldrich; Merck KGaA, while DSS (cat. no. S0798) was purchased from MP Biomedicals, LCC., and CUR (cat. no. LH80S20) was purchased from J\&K Scientific, Ltd. (https://www.jkchemical.com). PEG 400 (cat. no. C1925030) was purchased from Aladdin Industrial Corporation (https://www.linkedin.com). The Easy Pure RNA kit (cat. no. N10312), TransScript ALL-in-One First-Strand cDNA Synthesis Super Mix (cat. no. N10117) and TransStart Tip Green qPCR Super Mix (cat. no. N10710) were all purchased from Beijing Transgen Biotech Co., Ltd. The Rabbit primary antibody against Axin2 (1:2,000; cat. no. GR3203132-3; Abcam) and HRP-conjugated secondary antibody (goat anti-rabbit IgG; 1:10,000; cat. no. ab6722; Abcam) were purchased from Xi'an Zhuangzhi Biotechnology Co., Ltd. (https://www.chemicalbook.com/ContactUs_186262.htm). All other reagents in the experiment were pure analytical pure grade.

Animals and drug administration. A total of 60 C57BL/6 male mice $(20 \pm 2 \mathrm{~g} ; 6-8$ weeks old) were obtained from the Laboratory Animal Center of Xi'an Jiaotong University. Mice were randomly divided into three groups (20 mice/group) as follows: Control group, AOM-DSS group and mice treated with AOM-DSS and $500 \mathrm{mg} / \mathrm{kg}$ of CUR per day through oral gavage. Mice were fed in an air-conditioned room at $22 \pm 2{ }^{\circ} \mathrm{C}$ and relative humidity of $55 \pm 5 \%$, received standard water and chow freely, with a $12 \mathrm{~h}$ light/dark cycle for 1 week prior to treatment. All experimental animal protocols were approved by the Northwest University Animal Ethics Committee (Xi'an, China, approval no. NWU-AWC-20190202M), and all procedures were in line with relevant ethical norms (euthanasia was used to treat the animals) (21). Sevoflurane (8\%; Xi'an Zhuangzhi Biotechnology Co., Ltd., https://www. chemicalbook.com/ContactUs_186262.htm) was used for anesthesia (21).

Mice in the AOM-DSS group were treated with $10 \mathrm{mg} / \mathrm{kg}$ $\mathrm{AOM}$ via intraperitoneal injection. After 7 days, mice were given 2\% DSS drinking water for 1 week plus regular drinking water for 2 weeks in one of three rounds to induce colorectal tumors. Mice treated with CUR were given $500 \mathrm{mg} / \mathrm{kg}$ CUR suspension, while mice in the other groups were given the same volume of vehicle control PEG 400 via oral gavage until the end of the experiment. The behavior of mice, changes in body weight, hematochezia and the number of dead mice were recorded daily. At week 10, the mice were sacrificed using inhaled $8 \%$ sevoflurane to harvest plasma and colorectal tissues for analysis. Mortality was verified by checking for a heartbeat and consciousness. Colorectal tissues were cut open longitudinally, washed in PBS and inspected under a dissection microscope (magnification, $\mathrm{x} 20$ ). Tumor size was determined as follows: $\pi \mathrm{x} \mathrm{d}^{2} / 4$, where $\mathrm{d}$ is the diameter of each tumor.

$R T$-qPCR. RT-qPCR analysis was performed according to the manufacturer's instructions. Total RNA was extracted from colorectal tumor tissues using the Easy Pure RNA kit. Each colonic tissue was ground with a pestle, with continuous addition of liquid nitrogen. Different amounts of lysates were added according to the weight of colorectal tissue $(1: 1)$ and incubated in a water bath at $56^{\circ} \mathrm{C}$ for $20 \mathrm{~min}$. The mixture was centrifuged at $9,710 \mathrm{x} \mathrm{g}$ for $5 \mathrm{~min}$ at room temperature to collect the supernatant. Equal volumes of $70 \%$ ethanol was subsequently added, mixed with the supernatant and centrifuged $9,710 \mathrm{x}$ g for $30 \mathrm{sec}$ at $4^{\circ} \mathrm{C}$. Finally, the mixture was centrifuged at $9,710 \mathrm{x} \mathrm{g}$ for $2 \mathrm{~min}$ at room temperature to completely remove the residual ethanol. A total of $30 \mu \mathrm{l}$ RNase-free water was added and the mixture was left to stand for $1 \mathrm{~min}$, prior to centrifugation $9,710 \mathrm{x} \mathrm{g}$ for $2 \mathrm{~min}$ at room temperature to elute the RNA. The quality of extracted RNA was measured using Nano-Drop 2000 (Shanghai Danding Trading Co., Ltd., https://www.china. cn/fenguangguangduji/4679745796.html) and subsequently reverse transcribed into cDNA using a cDNA synthesis kit for $15 \mathrm{~min}$ at room temperature.

The expression levels of $\beta$-catenin, cyclooxygenase- 2 (Cox-2), Axin2, interleukin (IL)- $1 \beta$ and $I L-6$ were determined using the SYBR Green PCR kit (Beijing Transgen Biotech Co., Ltd.) on an ABI7300 system (Applied Biosystems; Thermo Fisher Scientific, Inc.). The following thermocycling conditions were used for qPCR: Initial denaturation at $95^{\circ} \mathrm{C}$ for $3 \mathrm{~min}$, followed by 39 cycles of $5 \mathrm{sec}$ at $95^{\circ} \mathrm{C}$ and $1 \mathrm{~min}$ at $58^{\circ} \mathrm{C}$. Relative expression levels were quantified using the $2^{-\triangle \Delta C q}$ method (22) and normalized to GAPDH. The primer sequences used for qPCR are listed in Table I (https://pga.mgh. harvard.edu/primerbank).

Western blotting. Total protein was extracted by centrifuging $1 \mathrm{ml}$ ice-cold RIPA buffer (cat. no. BC3710; Beijing Solarbio Science \& Technology Co., Ltd.) with $10 \mu$ l phosphatase inhibitor, $10 \mu \mathrm{l}$ protease inhibitor and $10 \mu \mathrm{l}$ PMSF supplemented 
Table I. Primer sequences used for quantitative PCR.

\begin{tabular}{lll}
\hline Gene & \multicolumn{1}{c}{ Forward $\left(5^{\prime}-3^{\prime}\right)$} & \multicolumn{1}{c}{ Reverse $\left(5^{\prime}-3^{\prime}\right)$} \\
\hline GAPDH & AGGTCGGTGTGAACGGATTTG & TGTAGACCATGTAGTTGAGGTCA \\
$\beta$-catenin & CAGCTTGAGTAGCCATTGTCC & GAGCCGTCAGTGCAGGAG \\
Axin 2 & TGCATCTCTCTCTGGAGCTG & ACTGACCGACGATTCCATGT \\
IL-1 $\beta$ & GCAACTGTTCCTGAACTCAACT & ATCTTTTGGGGTCCGTCAACT \\
IL-6 & TAGTCCTTCCTACCCCAATTTCC & TTGGTCCTTAGCCACTCCTTC \\
Cox-2 & TTCAACACACTCTATCACTGGC & AGAAGCGTTTGCGGTACTCAT
\end{tabular}

IL, interleukin; Cox-2, cyclooxygenase-2.

with 10-20 mg of grounded colorectal tissues, at 9,710 x $\mathrm{g}$ for $30 \mathrm{~min}$ at $4^{\circ} \mathrm{C}$. Protein concentration was determined using a bicinchoninic acid kit (cat. no. PC0020; Beijing Solarbio Science \& Technology Co., Ltd.). Samples were mixed with $2 \mathrm{X}$ sample buffer supplemented with $0.5 \mathrm{~mol} / 1 \mathrm{Tris}-\mathrm{HCl}$ $(\mathrm{pH}=6.8), 10 \%$ SDS, 50\% glycerol, $\beta$-mercaptoethanol and $1 \%$ bromophenol blue. (Xi'an Zhuangzhi Biotechnology Co., Ltd., https://www.chemicalbook.com/ContactUs_186262. $\mathrm{htm})$. The mixture was boiled at $100^{\circ} \mathrm{C}$ for $5-8 \mathrm{~min}$. Proteins (50-100 $\mu \mathrm{g})$ were separated using SDS-PAGE with $10 \%$ concentrated glue and $15 \%$ separated glue and transferred onto PVDF membranes (Pall Corporation) using transfer buffer supplemented with $10 \mathrm{X}$ electrode buffer and methanol (Xi'an Zhuangzhi Biotechnology Co., Ltd.). The membranes were blocked with 5\% non-fat milk (Inner Mongolia Yili Industrial Group Limited by Share Ltd., https://www.yili. com/cms/index\#section-1) for $2 \mathrm{~h}$ at room temperature and incubated with primary antibody against Axin 2 for $12 \mathrm{~h}$ at $4^{\circ} \mathrm{C}$ $(1: 2,000)$. Following the primary incubation, membranes were incubated with HRP-conjugated rabbit secondary antibodies $(1: 10,000)$ for $2 \mathrm{~h}$ at room temperature. Protein bands were visualized using an enhanced chemiluminescence kit (cat. no. c6100460100, Xi'an Zhuangzhi Biotechnology Co., Ltd.). GAPDH was used as the loading control (1:10,000; cat. no. 20536IAP; ProteinTech Group).

Hematoxylin and eosin $(H \& E)$ staining and IHC. H\&E staining was performed as previously described (23). Briefly, fresh colorectal tissue was placed in a glass dish filled with physiological saline (Xi'an Zhuangzhi Biotechnology Co., Ltd.) and washed several times. One third of the colorectal tissue at the anal end was placed in an embedding box and fixed with $4 \%$ paraformaldehyde overnight at $4^{\circ} \mathrm{C}$. Tissue sections were subsequently cut into $4-\mu \mathrm{m}$-thick sections and dewaxed in a series of xylene at about $60^{\circ} \mathrm{C}$. Pathological changes of the colorectal tissues were observed via H\&E staining for 15-20 min at room temperature.

For IHC analysis, samples were fixed with $40 \%$ paraformaldehyde for 24-48 h at room temperature, embedded in paraffin, and blocked with goat serum (Beijing Zhongshan Jinqiao Biology Technology Co., Ltd., http://www.zsbio. com) for $30 \mathrm{~min}$ at room temperature. Tissue sections were incubated with anti-Axin 2 (1:150) overnight at $4^{\circ} \mathrm{C}$, and subsequently incubated with a secondary antibody for $50 \mathrm{~min}$ at room temperature, followed by addition of
HRP-labeled streptavidin triple-antibody. Tissue sections were stained with 3,3'-diaminobenzidine for $50 \mathrm{sec}$ at $-20^{\circ} \mathrm{C}$, and Axin2 expression was observed under a light microscope (Eclipse C1) http://zh.medwow.com/med/confocal-microscope/nikon/eclipse-c1-plus/33643.model-spec. The results were analyzed using ImageJ v1.51 software (National Institutes of Health).

Statistical analysis. Statistical analysis was performed using GraphPad Prism v8.0.1 software (GraphPad Software, Inc.). At least three mice in each group were analyzed in the experiments. RT-qPCR and western blot analyses were performed three times, while all other experiments were performed once, and data are presented as the mean \pm standard deviation. One-way ANOVA and Bonferroni's post hoc test were used to compare differences in normally distributed data, and singularity of variance and independence between three groups. One-way ANOVA and Bonferroni's post hoc test were used to compare differences between three independent groups. $\mathrm{P}<0.05$ was considered to indicate a statistically significant difference.

\section{Results}

CUR suppresses AOM-DSS induced colorectal tumorigenesis in mice. The animal experimental scheme is presented in Fig. 1A. The effects of CUR on AOM-DSS induced CRC was investigated simultaneously. The results demonstrated that treatment with CUR significantly decreased the colorectal tumor number and tumor size (The maximum tumor diameter is about $11 \mathrm{~mm}$ ) compared with the AOM-DSS treated group. The average number of tumors in the AOM-DSS group was $8.25 \pm 3.24$. Following administration of CUR, the average total number of tumors in mice decreased to $5.25 \pm 2.65(\mathrm{P}=0.0018)$, while the tumor size decreased from $45.86 \pm 29.86 \mathrm{~mm}^{2}$ to $13.89 \pm 9.99 \mathrm{~mm}^{2}(\mathrm{P}=0.0057$; Fig. $1 \mathrm{~B}$ and $\mathrm{C})$. The mice were not sacrificed in the middle of the experiment in order to assess the tumor size at different time points since the AOM-DSS induced CRC model is a long-term and integral process. Thus, sacrificing the mice in the middle of the experiment may have resulted in failure of the whole animal model (no tumors in mice).

CUR exhibits slower weight loss and has little effect on the survival rate of AOM-DSS induced CRC mice. Mice were 
A
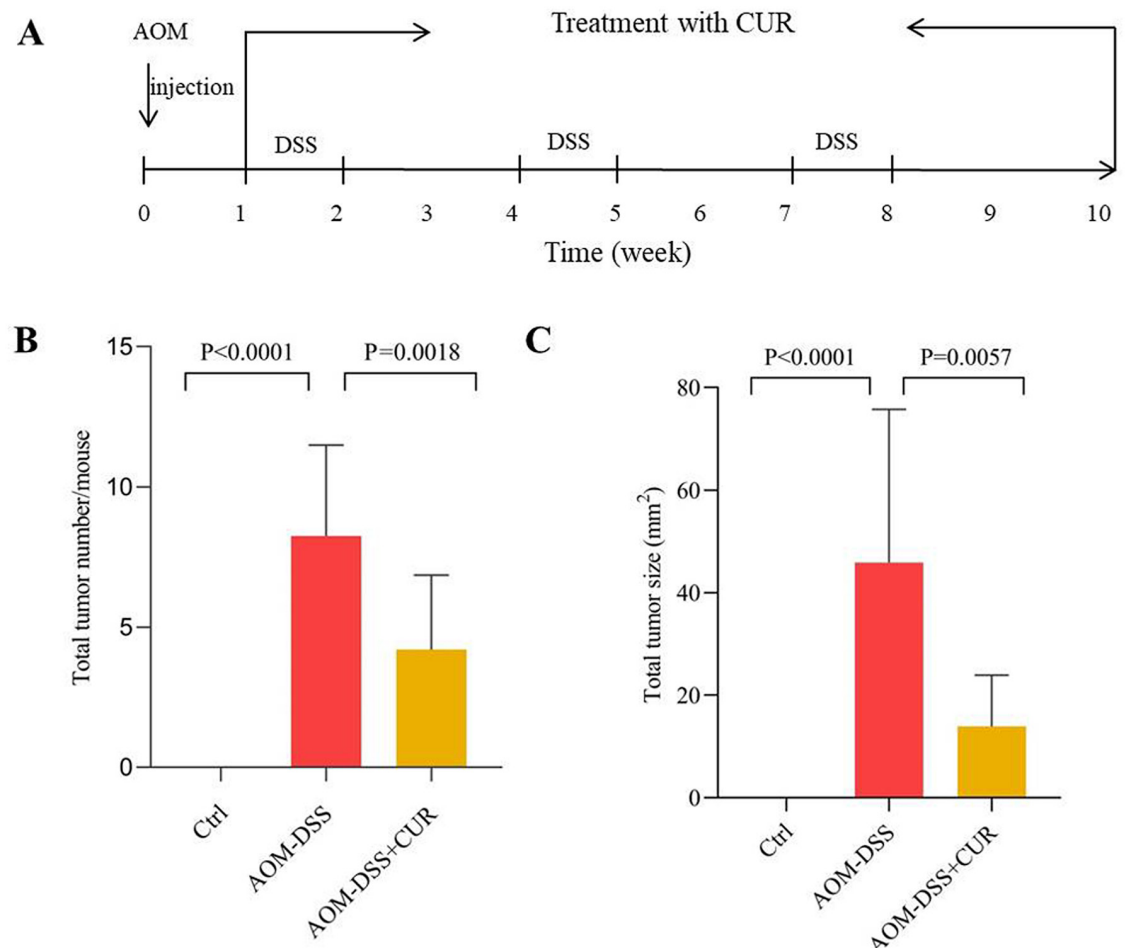

C

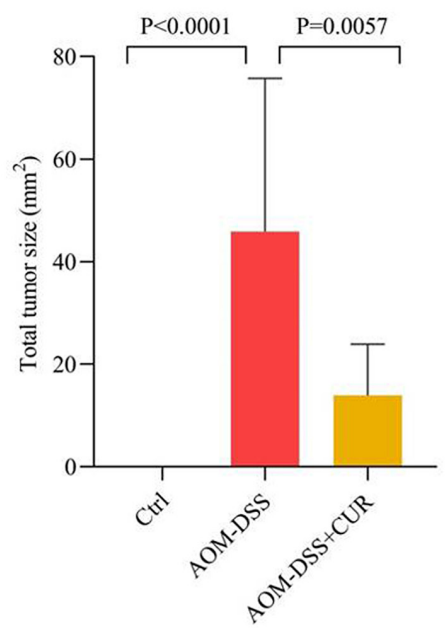

Figure 1.CUR decreases AOM-DSS induced tumorigenesis. (A) Animal experimental scheme of AOM-DSS induced colorectal cancer. (B and C) Quantification of colorectal tumor in mice (n=6-8/group). (B) Total colorectal tumor number of the three groups. (C) Total colorectal tumor size of the three groups. Data are presented as the mean \pm standard deviation. CUR, curcumin; AOM, azoxymethane; DSS, dextran sodium sulfate; Ctrl, control.

A
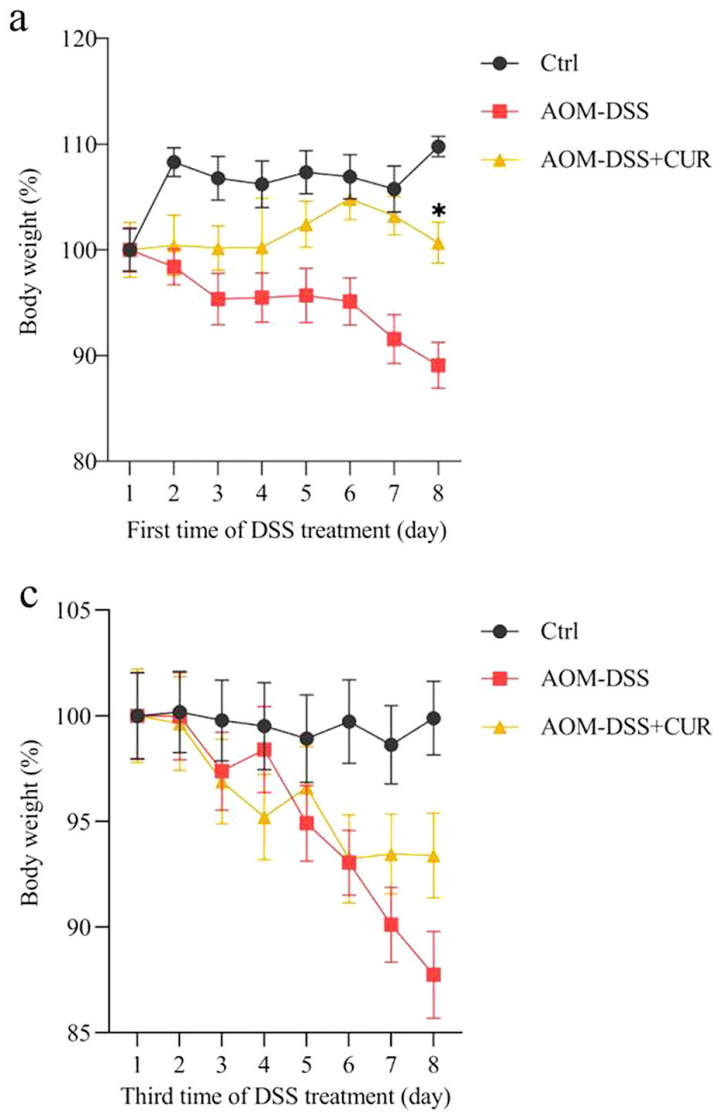

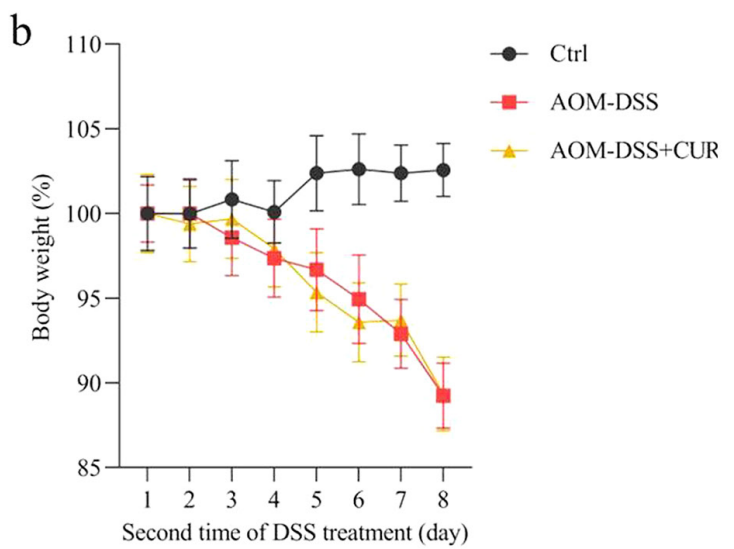

B

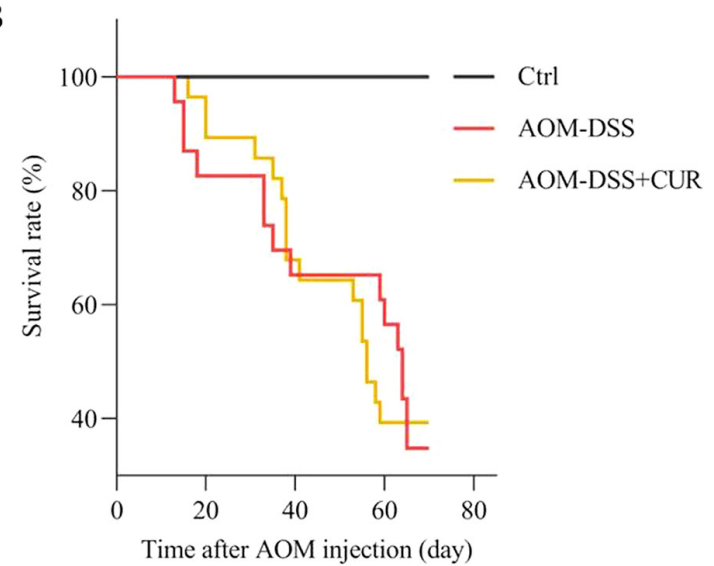

Figure 2. CUR exhibits slower weight loss and has little effect on the mortality rate of AOM-DSS induced colorectal cancer mice. (A) The change in body weight of mice administered 2\% DSS drinking water. The change in body weight of mice within 7 days from the (Aa) first round, (Ab) second round and (Ac) third round following administration of $2 \%$ DSS. (B) Survival curve of the three groups during the entire experiment ( $\mathrm{n}=18-20 /$ group). Data are presented as the mean \pm standard deviation. P<0.05. CUR, curcumin; AOM, azoxymethane; DSS, dextran sodium sulfate; Ctrl, control. 
A
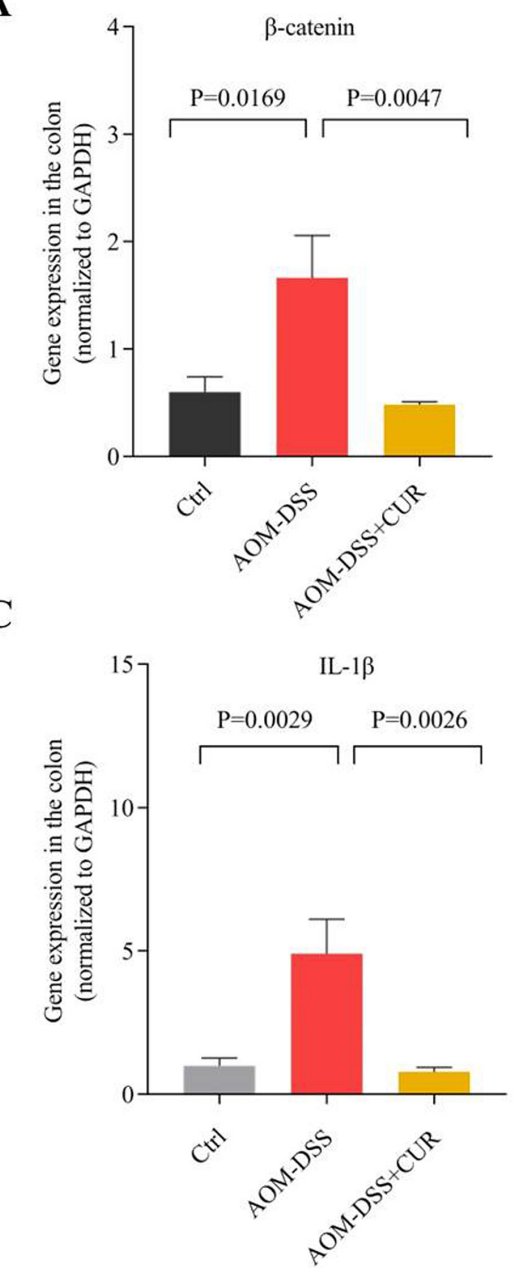

B
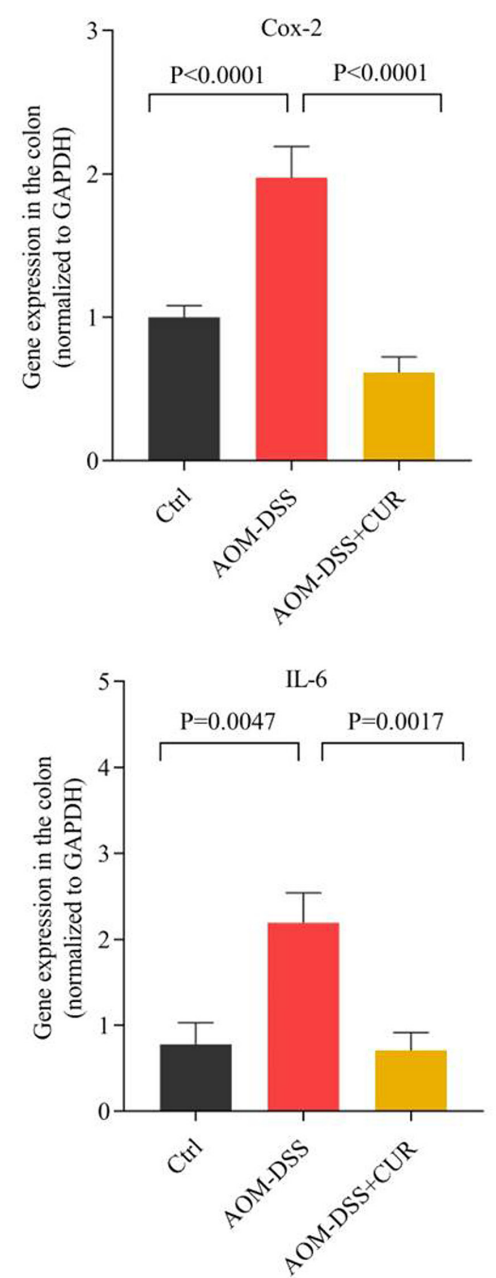

Figure 3. CUR downregulates the expression of pro-inflammatory cytokines and $\beta$-catenin. Reverse transcription-quantitative PCR analysis of (A) $\beta$-catenin, (B) Cox-2, (C) $I L-1 \beta$ and (D) $I L-6$ in colorectal tissues of AOM-DSS or CUR-treated AOM-DSS mice (n=5-7/group). Data are presented as the mean \pm standard deviation. CUR, curcumin; AOM, azoxymethane; DSS, dextran sodium sulfate; Cox-2, cyclooxygenase-2; IL, interleukin; Ctrl, control.

treated with $500 \mathrm{mg} / \mathrm{kg}$ CUR for 7 weeks, and the body weight of the mice was recorded every day following administration of $2 \%$ DSS water. During the three rounds of 7 days of DSS treatment, little body weight was lost in the first 3-5 days. Notably, the body weight rapidly decreased on day 6, whereby 7-8 mice died due to excessive weight loss (the maximum percentage weight loss was $12.26 \%$ during the full course of the experiment). In addition to the rapid weight loss, the mental state of the mice weakened following administration of $2 \%$ DSS water. Thus, for humane endpoints, $8 \%$ sevoflurane was used to euthanize the mice.

The results demonstrated that CUR significantly slowed the weight loss of mice on the last day of the first round of DSS water compared with the AOM-DSS group $(\mathrm{P}<0.05$; Fig. 2Aa). However, no significant differences were observed in mortality between the AOM-DSS (65\%) and AOM-DSS+CUR (60\%) groups (Fig. 2B). This may be due to the oral gavage treatment period of vehicle control or CUR, and the small sample size. The oral gavage is a common technique used in rodent experiments and the most straight forward approach involving passing a feeding needle through the mouth and into the esophagus (24). However, this technique is associated with potential adverse effects, including (but not limited to) esophageal trauma, aspiration pneumonia and weight loss (24), which may have led to no significant differences in the mortality rates between the AOM-DSS and AOM-DSS+CUR groups.

CUR downregulates the expression of pro-inflammatory cytokines and protumorigenic proteins. RT-qPCR analysis demonstrated that the expression levels of $I L-1 \beta, I L-6$, Cox -2 $(\mathrm{P}<0.0001)$ and $\beta$-catenin $(\mathrm{P}<0.01)$ significantly decreased in the CUR-treated group compared with the AOM-DSS group (Fig. 3), suggesting that CUR suppresses AOM-DSS induced tumorigenesis by downregulating cytokines expression.

The H\&E staining results demonstrated that treatment with AOM-DSS disordered cell arrangement, enlarged the nucleus and imbalanced the ratio of nuclear-cytoplasmic cell morphology compared with the control group (Fig. 4A).

IHC analysis demonstrated that AOM-DSS increased the expression levels of the tumorigenic markers, proliferating cell nuclear antigen (PCNA) and $\beta$-catenin, while treatment with CUR significantly decreased PCNA and $\beta$-catenin expression (both $\mathrm{P}<0.0001$; Fig. 4B). Taken together, these results suggest that CUR attenuates tumor occurrence by downregulating the expression of $\beta$-catenin and pro-inflammatory cytokines, and 


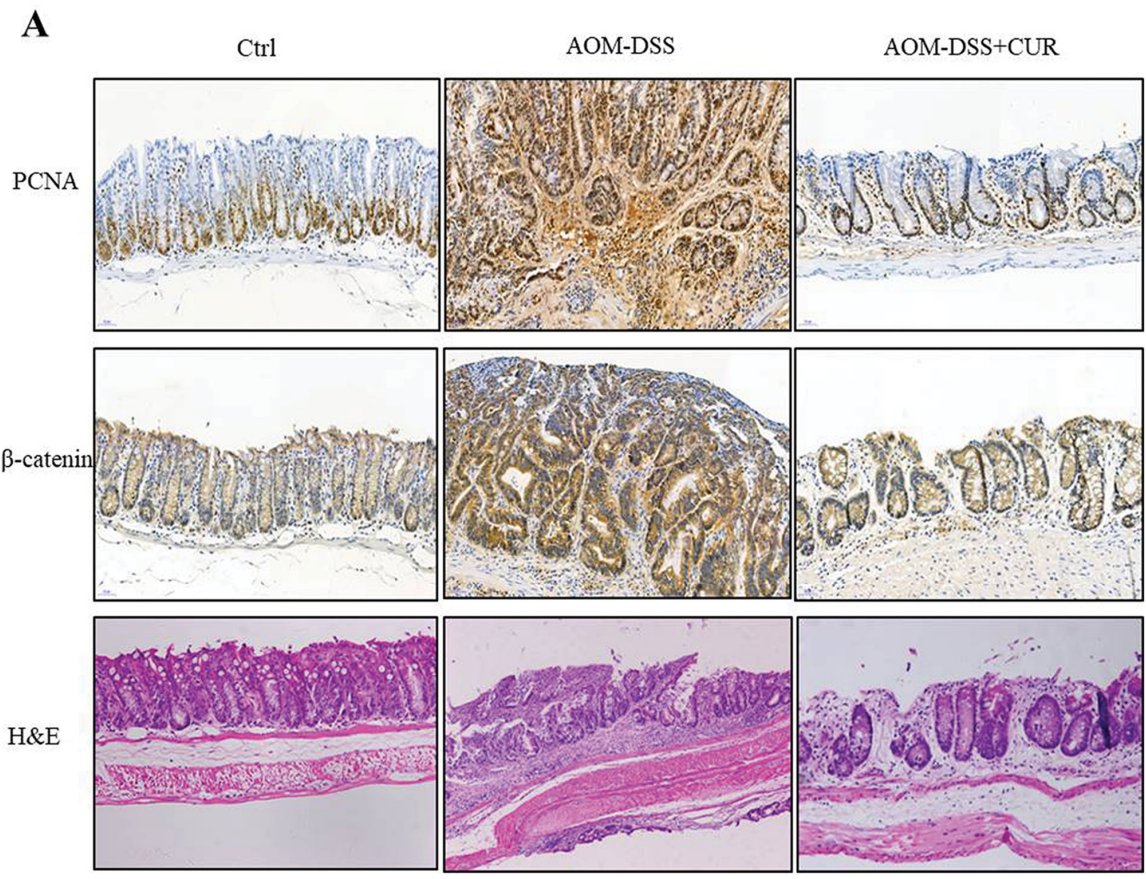

B
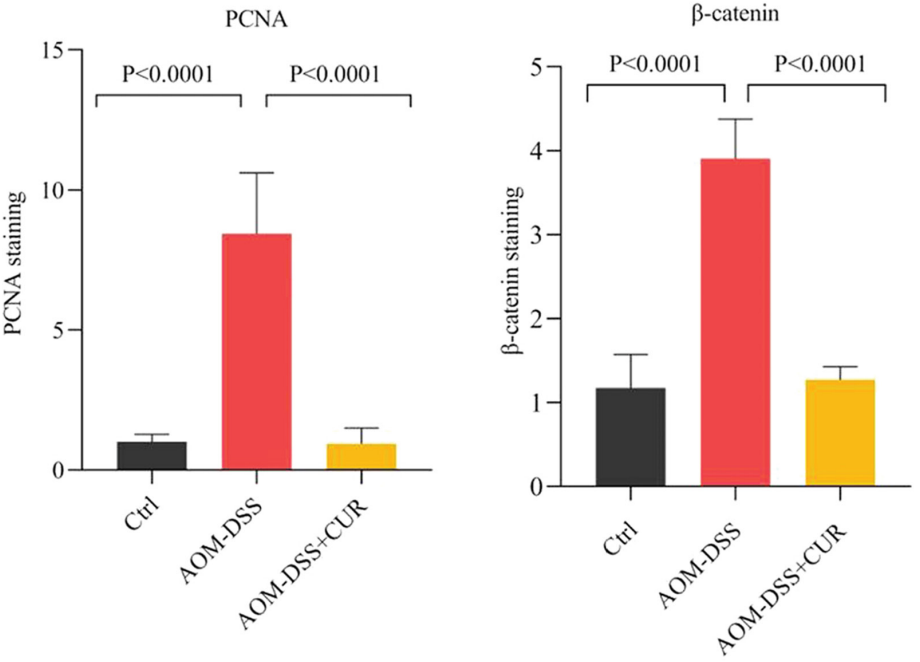

Figure 4. CUR decreases protumorigenic protein expression. (A) Representative images of immunohistochemical and H\&E staining for PCNA and $\beta$-catenin, (magnification, $x 20 ; n=4 /$ group). (B) Quantification of PCNA and $\beta$-catenin immunohistochemical staining in the colorectal tissue ( $\mathrm{n}=4 / \mathrm{group}$ ). Data are presented as the mean \pm standard deviation. CUR, curcumin; H\&E, hematoxylin and eosin; PCNA, proliferating cell nuclear antigen; Ctrl, control; AOM, azoxymethane; DSS, dextran sodium sulfate.

decreasing tumor cell proliferation, which further validates the anticancer effect of CUR in vivo.

\section{CUR attenuates AOM-DSS induced CRC by downregulating} Axin2. Axin2 is one of the important regulatory downstream genes of the Wnt/ $\beta$-catenin signaling pathway, which is involved in several biological functions, including proliferation, mutation, migration and apoptosis (25-28). The results of the present study demonstrated that treatment with CUR suppressed Axin2 expression in the colorectal tissue of mice compared with the AOM-DSS group ( $\mathrm{P}=0.0004$; Fig. 5A). These results were consistent with those of western blotting (Fig. 5B). Furthermore, IHC analysis demonstrated that CUR decreased Axin2 expression induced by AOM-DSS $(\mathrm{P}=0.0480$; Fig. 5C). Collectively, these results suggest that CUR attenuates AOM-DSS induced CRC by downregulating
Axin2, which is as important downstream target gene involved in the Wnt/ $\beta$-catenin signaling pathway (14), thus indicating the potential anticancer target of CUR.

\section{Discussion}

CUR, a spice widely used in cooking condiments for hundreds of years, is a natural extract from rhizome of Curcuma longa $(5,29)$. Studies have confirmed that CUR exerts antioxidant, antibacterial, anti-inflammatory, antiproliferation and anticancer effects (8-11). CUR is unstable and easily degrades (30-32). In vitro studies have demonstrated that the anticancer effects are exerted by CUR rather than its degradation products (30-32). However, the in vivo molecular mechanism for the anticancer effect of CUR remains to be elucidated. One of the mechanism studies in vitro revealed 
A

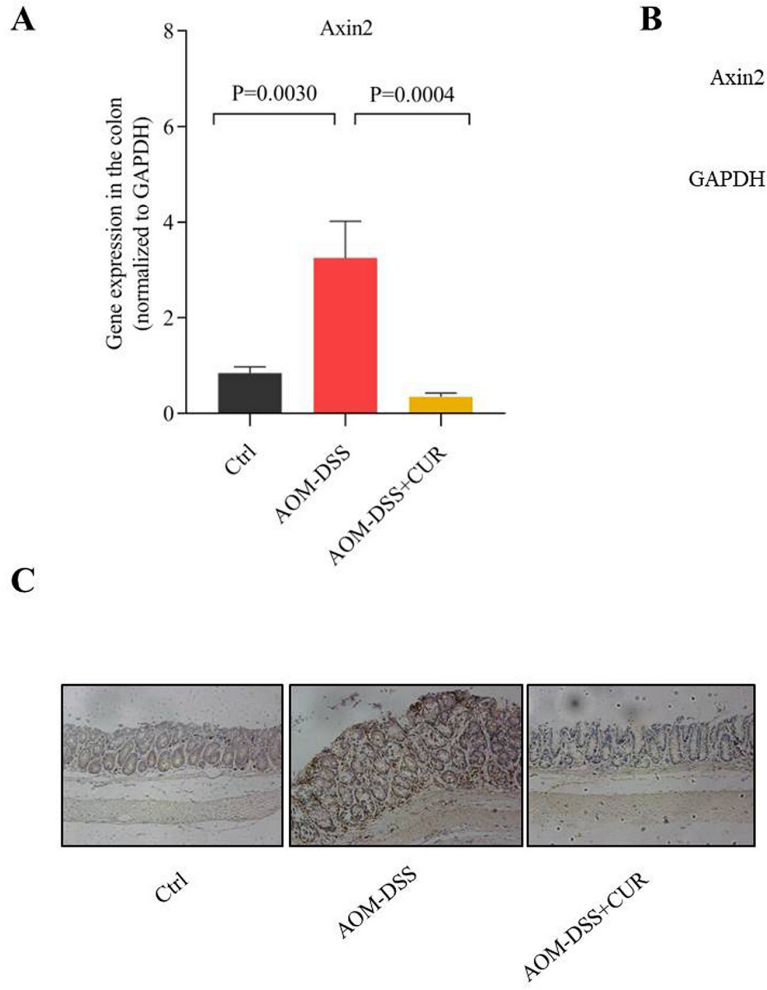

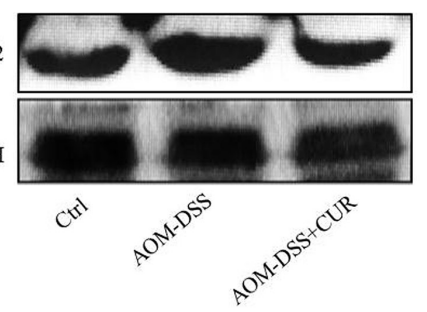

Axin2

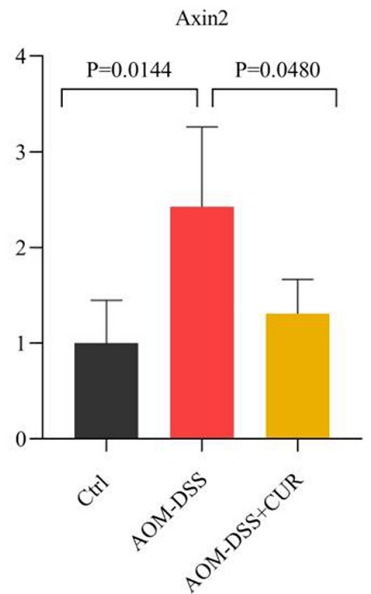

Figure 5. CUR inhibits tumorigenesis by suppressing Axin2 expression. (A) Reverse transcription-quantitative PCR analysis of Axin2 in colorectal tissues of AOM-DSS or CUR-treated AOM-DSS mice (n=7-9/group). (B) Western blot analysis of Axin2 protein expression in colorectal tissues of AOM-DSS or CUR-treated AOM-DSS mice. Axin2 expression decreased following treatment with CUR compared with the AOM-DSS group. (C) Immunohistochemical staining and quantification results of Axin2 expression, (magnification, $x 20 ; n=4 /$ group). Data are presented as the mean \pm standard deviation. CUR, curcumin; AOM, azoxymethane; DSS, dextran sodium sulfate; Ctrl, control.

that CUR can inhibit Axin2 expression in the CRC cell line, HCT116, and regulate the $\mathrm{Wnt} / \beta$-catenin signaling pathway (15), while the effect and mechanisms in vivo remain largely unknown. Thus, the present study chose the high reproducibility and potency AOM-DSS induced CRC model instead of the xenograft model, as the AOM-DSS induced CRC model recapitulates the aberrant crypt foci-adenoma-carcinoma sequence that occurs in human CRC well (33), while the xenograft model occurs by injecting colon cancer cells to the subcutaneous, which cannot fully mimic the pathology of CRC in humans. The results of the present study highlighted the effect of CUR against CRC in vivo, and demonstrated that the in vivo mechanism occurs via regulation of the Wnt/ $\beta$-catenin signaling pathway by decreasing Axin2 expression in AOM-DSS induced CRC.

The results of the present study demonstrated that CUR attenuated AOM-DSS induced CRC in mice, which is consistent with previous studies that have reported the anticancer effects of CUR (17,18,34-36). The results of the present study demonstrated that administration of CUR significantly decreased both the tumor number and tumor size compared with the AOM-DSS treatment group. Dou et al (36) reported that CUR also suppresses tumor growth in a xenograft CRC model, where $200 \mathrm{mg} / \mathrm{kg}$ CUR attenuates cell growth in the xenograft model via subcutaneous injection of human colon cancer cells SW480 into the mice. Lv et al (37) demonstrated similar results in a breast cancer model, which indicated that CUR inhibits tumor growth in a xenograft breast tumor model by subcutaneous injection of MDA-MB-231 cells in mice. These results are consistent with the present study, demonstrating the inhibitory effects of CUR on tumor growth. In addition, the results of the present study demonstrated that CUR downregulated the expression of pro-inflammatory cytokines, which further supports the hypothesis that inflammation plays an important role in the progress of tumorigenesis. A previous study demonstrated that inflammation is associated with at least $15 \%$ of malignant tumors, worldwide (38). Patients with inflammatory bowel disease (IBD) have a higher risk of developing CRC compared with the general population (39). In addition, CUR has been extensively reported for its efficacy in the prevention and treatment of several inflammatory diseases, such as IBD, rheumatoid arthritis, systemic lupus erythematosus (SLE), atherosclerosis and multiple sclerosis (40). Chen et al (41) demonstrated that CUR prevents cytokines production $(I L-1 \beta, I L-6$ and $T N F-\alpha)$ induced by hyperosmotic stimulation in corneal epithelial cells. $\beta$-catenin is the downstream effector of the Wnt/adenomatous polyposis coli protein (APC)/ $\beta$-catenin signaling pathway, which controls the proliferation of colon epithelial cells and is generally imbalanced in colon aberrant crypt foci and tumors $(42,43)$. TNF- $\alpha$ is an important inflammatory cytokine in the early stages of inflammation, which is mainly produced by monocytes and macrophages. TNF- $\alpha$ can activate the cytokine cascade reaction, resulting in a waterfall effect and triggering the synthesis of secondary inflammatory mediators, including IL-1 $\beta$ and IL-6 $(44,45)$. IL- $1 \beta$ and IL- 6 are important indicators for assessing inflammatory reactions 
and therapeutic effects in clinical and basic research $(44,45)$. Taken together, the results of the present study suggest that the antitumor effects of CUR may be partially exerted through its anti-inflammatory effects.

The present study demonstrated that CUR suppressed tumorigenesis by downregulating the $\mathrm{Wnt} / \beta$-catenin signaling pathway. The $\mathrm{Wnt} / \beta$-catenin signaling pathway is important for normal growth and development, and is one of the most frequently dysregulated pathways in CRC (46). Aberrant activation of this pathway is associated with cell proliferation, invasive behavior and cell resistance, suggesting its potential value as a therapeutic target in CRC treatment (47). Axin2, which is one of the main downstream target genes (48), acts as a negative feedback regulator of the stability of the Wnt/ $\beta$-catenin signaling pathway in CRC (49). In the absence of stimulation, $\beta$-catenin is phosphorylated by a multiprotein complex containing adenomatous polyposis coli (APC), casein kinase 1, glycogen synthase kinase $3 \beta$ and either Axin1 or Axin2, subsequently undergoing ubiquitin-dependent proteolysis (50). Under abnormal conditions, the multiprotein complex is disintegrated, resulting in the accumulation and nuclear translocation of $\beta$-catenin (51-53). $\beta$-catenin is associated with the lymphoid enhancer factor/T-cell factor family (TCF), converting them from transcription repressors to activators, thereby activating several Wnt-responsive genes (51-53). Compared with Axin1, Axin2 is more likely to promote $\beta$-catenin degradation even in the presence of upstream signaling, which is a characteristic of negative feedback regulation (51-53). However, Wu et al (54) demonstrated that endogenous Axin 2 promotes the epithelial-to-mesenchymal transition (EMT) initiated by $\beta$-catenin/TCF in $\beta$-catenin-mutant and APC mutant CRC. Upregulated Axin2 levels in CRC trigger a significant increase in Snaill activity and induce EMT, while silencing of Axin2 initiates mesenchymal-like epithelioid-like conversion, which not only downregulates Snaill but also triggers extensive changes in the classical Wnt signaling transcriptome (54). These studies have demonstrated that Axin2 can function as an effective tumor promoter rather than a tumor suppressor (54). Yan et al (16) came to the same conclusion by analyzing the gene expression profile produced by the CRC cell line, SW620, in which antisense oligo deoxy nucleotide transfection decreased $\beta$-catenin protein levels. In the present study, Axin 2 was demonstrated to be the target gene induced by decreased $\beta$-catenin. Notably, the present study performed experiments on human colon tumor samples, where Axin 2 mRNA expression was upregulated in colorectal tumors when the $\mathrm{Wnt} / \beta$-catenin pathway was activated. These results, along with the aforementioned studies, indicate the importance of Axin2 in the $W n t / \beta$-catenin signaling pathway in CRC. The results of the present study demonstrated that CUR inhibited CRC via Axin 2 downregulation in the $\mathrm{Wnt} / \beta$-catenin pathway, further demonstrating the molecular mechanism of the anticancer effects of CUR in vivo. These results suggest that CUR may be a promising drug for the prevention and treatment of CRC. However, further studies are required to confirm that CUR regulates Axin2.

Previous studies have reported that the molecular mechanisms of CUR anticancer effects include several other signaling pathways, such as the PI3k/Akt-1/Mtor (55-57), Akt/GSK-3 $\beta$ (58) and NF- $\kappa$ B signaling pathways (59). The PI3K/Akt-1/mTOR signaling pathway is important in cell proliferation, cell survival, cell development and signal transduction during cellular metabolism (60). A previous study demonstrated that CUR induces $\mathrm{G}_{2} / \mathrm{M}$ arrest and autophagy by suppressing the Akt/mTOR/p70S6K pathway (61). Zhao et al (56) validated that CUR inhibits cancer cell proliferation and invasion by downregulating the AKT/mTOR signaling pathway in human melanoma cells. CUR induces apoptotic cell death through GSK-3 $\beta$ activation in NCCIT human embryonic carcinoma cells (58). The NF- $\kappa \mathrm{B}$ signaling pathway abates the survival and proliferation of cancer cells (59). CUR inhibits NF- $\mathrm{KB}$ reporter activity, which is associated with decreased levels of phosphorylated-IкB $\alpha$ and expression of its downstream target genes, Cox-2 and cyclin D1, to act as an anticancer effector (59).

In conclusion, a better understanding of CUR roles and mechanisms involved in colorectal tumorigenesis may aid in the development of novel therapeutic targets of CRC, promoting the progress of effective, safe and mechanism-based strategies to decrease the risks of CRC.

\section{Acknowledgements}

Not applicable.

\section{Funding}

The present study was supported by the National Natural Science Foundation of China (grant no. 81702832).

\section{Availability of data and materials}

The datasets used and/or analyzed during the present study are available from the corresponding author upon reasonable request.

\section{Authors' contributions}

YW conceived and designed the present study. JH and XD performed the experiments and analyzed the datasets. $\mathrm{JH}$ was a major contributor in drafting the initial manuscript. JG, YL, ZH and ZC helped perform the experiments. All authors have read and approved the final manuscript and agree to be accountable for all aspects of the research in ensuring that the accuracy or integrity of any part of the work are appropriately investigated and resolved.

\section{Ethics approval and consent to participate}

All experimental animal protocols were approved by the Northwest University Animal Ethics Committee (Xi'an, China; approval no. NWU-AWC-20190202M), and all procedures were in line with relevant ethical norms (21).

\section{Patient consent for publication}

Not applicable. 


\section{Competing interests}

The authors declare that they have no competing interests.

\section{References}

1. Isnida IN, Iekhsan O, Faridah A, Nordin H and Rakesh N: Mechanism of apoptosis induced by curcumin in colorectal cancer. Int J Mol Sci 20: 2454, 2019

2. Bahrami A, Khazaei M, Hasanzadeh M, ShahidSales S, Mashhad MJ, Farazestanian M, Sadeghnia HR, Rezayi M, Maftouh M, Hassanian SM and Avan A: Therapeutic potential of targeting PI3K/AKT pathway in treatment of colorectal cancer: Rational and progress. J Cell Biochem 119: 2460-2469, 2018

3. Wong KE, Ngai SC, Chan KG, Lee LH, Goh BH and Chuan LH Curcumin nanoformulations for colorectal cancer: A review. Front Pharmacol 10: 152, 2019.

4. Molodecky NA, Soon IS, Rabi DM, Ghali WA, Ferris M, Chernoff G, Benchimol EI, Panaccione R, Ghosh S, Barkema HW and Kaplan GG: Increasing incidence and prevalence of the inflammatory bowel diseases with time, based on systematic review. Gastroenterology 142: 46-54, 2012.

5. Goel A, Kunnumakkara AB and Aggarwal BB: Curcumin as 'Curecumin': From kitchen to clinic. Biochem Pharmacol 75: 787-809, 2008

6. Ahmad A, Sakr WA and Rahman KM: Novel targets for detection of cancer and their modulation by chemopreventive natura compounds. Front Biosci (Elite ED) 4: 410-425, 2012.

7. Nobili S, Lippi D, Witort E, Donnini M, Bausi L, Mini E and Capaccioli S: Natural compounds for cancer treatment and prevention. Pharmacol Res 59: 365-378, 2009.

8. Srimal RC and Dhawan BN: Pharmacology of diferuloyl methane (curcumin), a non-steroidal anti-inflammatory agent. J Pharm Pharmacol 25: 447-452, 1973.

9. Sugiyama Y, Kawakishi S and Osawa T: Involvement of the beta-diketone moiety in the antioxidative mechanism of tetrahydrocurcumin. Biochem Pharmacol 52: 519-525, 1996.

10. Mahady GB, Pendland SL, Yun G and Lu ZZ: Turmeric (Curcuma longa) and curcumin inhibit the growth of helicobacter pylori, a group 1 carcinogen. Anticancer Res 22 4179-4181, 2002.

11. Kuttan R, Bhanumathy P, Nirmala K and George MC: Potential anticancer activity of turmeric (curcuma longa). Cancer Lett 29: 197-202, 1985

12. Gupta SC, Patchva S and Aggarwal BB: Therapeutic roles of curcumin: Lessons learned from clinical trials. AAPS J 15 : 195-218, 2013

13. Hewlings SJ and Kalman DS: Curcumin: A review of its' effects on human health. Foods 6: 92, 2017.

14. Moradi-Marjaneh R, Hassanian SM, Shahidsalea S, Avan A and Khazaei M: Curcumin effects on the wnt signaling pathway in colorectal cancer stem cells. Basic Clin Cancer Res 10: 33-48, 2018.

15. Srivastava NS and Srivastava RA: Curcumin and quercetin synergistically inhibit cancer cell proliferation in multiple cancer cells and modulate Wnt/ $\beta$-catenin signaling and apoptotic pathways in A375 cells. Phytomedicine 52: 117-128, 2019.

16. Yan D, Wiesmann M, Rohan M, Chan V, Jefferson AB, Guo L, Sakamoto D, Caothien RH, Fuller JH, Reinhard C, et al: Elevated expression of axin2 and hnkd mRNA provides evidence that Wnt/beta-catenin signaling is activated in human colon tumors. Proc Natl Acad Sci USA 98: 14973-14978, 2001.

17. Hai J, Fan Q, Yan W, Xu Y and Yan S: Curcumin inhibits cell proliferation and induces apoptosis of human non-small cell lung cancer cells through the upregulation of miR-192-5p and suppression of PI3K/Akt signaling pathway. Oncol Rep 34 2782-2789, 2015

18. Zhen L, Fan D, Yi X, Cao X, Chen D and Wang L: Curcumin inhibits oral squamous cell carcinoma proliferation and invasion via EGFR signaling pathways. Int J Clin Exp Pathol 7 : 6438-6446, 2014

19. Yu H, Xie Y, Zhou Z, Wu Z, Dai X and Xu B: Curcumin regulates the progression of colorectal cancer via LncRNA NBR2/AMPK pathway. Technol Cancer Res Treat 18 : $1533033819870781,2019$.

20. Shakibaei M, Mobasheri A, Lueders C, Busch F, Shayan P and Goel A: Curcumin enhances the effect of chemotherapy against colorectal cancer cells by inhibition of NF- $\mathrm{KB}$ and src protein kinase signaling pathways. PLoS One 8: e57218, 2013.
21. Hawkins P, Prescott MJ, Carbone L, Dennison N, Johnson C, Makowska IJ, Marquardt N, Readman G, Weary DM and Golledge HD: A good death? Report of the second newcastle meeting on laboratory animal euthanasia. Animals (Basel) 9: 50, 2016.

22. Livak KJ and Schmittgen TD: Analysis of relative gene expression data using real-time quantitative PCR and the 2(-Delta Delta $\mathrm{C}(\mathrm{T})$ ) method. Methods 25: 402-408, 2001

23. Guo Y, Liu Y, Zhang C, Su ZY, Li W, Huang MT and Kong AN The epigenetic effects of aspirin: The modification of histone H3 lysine 27 acetylation in the prevention of colon carcinogenesis in azoxymethane- and dextran sulfate sodium-treated CF-1 mice. Carcinogenesis 37: 616-624, 2016.

24. Jones CP, Boyd KL and Wallace JM: Evaluation of mice undergoing serial oral gavage while awake or anesthetized. J Am Assoc Lab Anim Sci 6: 805-810, 2016

25. Salahshor S, Goncalves J, Chetty R, Gallinger S and Woodgett JR: Differential gene expression profile reveals deregulation of pregnancy specific beta 1 glycoprotein 9 early during colorectal carcinogenesis. BMC Cancer 5: 66, 2005.

26. Gunes EG, Pinarbasi E and Pinarbasi H: AXIN2 polymorphism and its association with astrocytoma in a turkish population. Mol Med Rep 3: 705-709, 2010.

27. Kanzaki H, Ouchida M, Hanafusa H, Yano M, Suzuki H, Aoe M, Imai K, Shimizu N, Nakachi K and Shimizu K: Single nucleotide polymorphism of the AXIN2 gene is preferentially associated with human lung cancer risk in a Japanese population. Int J Mol Med 18: 279-284, 2006.

28. Aristizabal-Pachon AF, Carvalho TI, Carrara HH, Andrade J and Takahashi CS: AXIN2 polymorphisms, the $\beta$-Catenin destruction complex expression profile and breast cancer susceptibility. Asian Pac J Cancer Prev 16: 7277-7284, 2015.

29. Yallapu MM, Jaggi M and Chauhan SC: Curcumin nanomedicine: A road to cancer therapeutics. Curr Pharm Des 19: 1994-2010, 2013

30. Sanidad KZ, Zhu J, Wang W, Du Z and Zhang G: Effects of stable degradation products of curcumin on cancer cell proliferation and inflammation. J Agric Food Chem 4: 9189-9195, 2016.

31. Gordon ON, Luis PB, Sintim HO and Schneider C: Unraveling curcumin degradation: Autoxidation proceeds through spiroepoxide and vinylether intermediates enroute to the main bicyclopentadione. J Biol Chem 290: 4817-4828, 2015.

32. Griesser M, Pistis V, Suzuki T, Tejera N, Pratt DA and Schneider C: Autoxidative and cyclooxygenase-2 catalyzed transformation of the dietary chemopreventive agent curcumin. J Biol Chem 286: 1114-1124, 2011.

33. De Robertis M, Massi E, Poeta ML, Carotti S, Morini S, Cecchetelli L, Signori E and Fazio VM: The AOM/DSS murine model for the study of colon carcinogenesis: From pathways to diagnosis and therapy studies. J Carcinog 10: 9, 2011.

34. Guo H, Xu YM, Ye ZQ, Yu JH and Hu XY: Curcumin induces cell cycle arrest and apoptosis of prostate cancer cells by regulating the expression of IkappaBalpha, c-jun and androgen receptor. Pharmazie 68: 431-434, 2013.

35. Ma J, Fang B, Zeng F, Pang H, Zhang J, Shi Y, Wu X, Cheng L, Ma C, Xia J and Wang Z: Curcumin inhibits cell growth and invasion through up-regulation of miR-7 in pancreatic cancer cells. Toxicol Lett 231: 82-91, 2014.

36. Dou H, Shen R, Tao J, Huang L, Shi H, Chen H, Wang Y and Wang T: Curcumin suppresses the colon cancer proliferation by inhibiting wnt $/ \beta$-catenin pathways via miR-130a. Front Pharmacol 8: 877, 2017.

37. Lv ZD, Liu XP, Zhao WJ, Dong Q, Li FN, Wang HB and Kong B: Curcumin induces apoptosis in breast cancer cells and inhibits tumor growth in vitro and in vivo. Int J Clin Exp Pathol 7: 2818-2824, 2014

38. Hynes MJ, Huang KM and Huang EH: Review paper: Implications of the 'Cancer Stem Cell' hypothesis on murine models of colon cancer and colitis-associated cancer. Vet Pathol 46: 819-835, 2009.

39. Ryan BM, Wolff RK, Valeri N, Khan M, Robinson D, Paone A, Bowman ED, Lundgreen A, Caan B, Potter J, et al: An analysis of genetic factors related to risk of inflammatory bowel disease and colon cancer. Cancer Epidemiol 38: 583-590, 2014.

40. Kahkhaie KR, Mirhosseini A, Aliabadi A, Mohammadi A, Mousavi MJ, Haftcheshmeh SM, Sathyapalan T and Sahebkar A: Curcumin: A modulator of inflammatory signaling pathways in the immune system. Inflammopharmacology 27: 885-900, 2019.

41. Chen M, Hu DN, Pan Z, Lu CW, Xue CY and Aass L: Curcumin protects against hyperosmoticity-induced Il-1beta elevation in human corneal epithelial cell via MAPK pathways. Exp Eye Res 90: 437-443, 2010. 
42. Morin PJ, Sparks AB, Korinek V, Barker N, Clevers H, Vogelstein B and Kinzler KW: Activation of beta-catenin-tcf signaling in colon cancer by mutations in beta-catenin or APC. Science 275: 1787-1790, 1997.

43. Korinek V, Barker N, Morin PJ, Wichen D, de Weger R, Kinzler KW, Vogelstein B and Clevers H: Constitutive transcriptional activation by a beta-catenin-tcf complex in APC-/-colon carcinoma. Science 275: 1784-1787, 1997.

44. Park SH, Kang K, Giannopoulou E, Yu Q, Kang K, Kim G, Park-Min KH and Ivashkiv LB: Type I interferons and the cytokine TNF cooperatively reprogram the macrophage epigenome to promote inflammatory activation. Nat Immunol 10: 1104-1116, 2017.

45. Wu Y, Liu Z, Wu W, Lin S, Zhang N, Wang H, Tan S, Lin P, Chen X, Wu L and Xu J: Effects of FM0807, a novel curcumin derivative, on lipopolysaccharide-induced inflammatory factor release via the ROS/JNK/p53 pathway in RAW264.7 cells. Biosci Rep 5: BSR20180849, 2018.

46. Mccubrey JA, Rakus D, Gizak A, Steelman LS, Abrams SL, Lertpiriyapong K, Fitagerald TL, Yang LV, Montalto G, Cervello M, et al: Effects of mutations in Wnt//-catenin, hedgehog, notch and PI3K pathways on GSK-3 activity-diverse effects on cell growth, metabolism and cancer. Biochim Biophys Acta 12: 2942-2976, 2016.

47. Bahrami A, Amerizadeh F, Shahidsales S, Khazaei M, Ghayour-Mobarhan M, Sadeghnia HR, Maftouh M, Hassanian SM and Avan A: Therapeutic potential of targeting Wnt $/ \beta$-catenin pathway in treatment of colorectal cancer: Rational and progress. J Cell Biochem 118: 1979-1983, 2017.

48. Jho E, Zhang T, Domon C, Joo CK, Freund JN and Costantini F: Wnt/beta-catenin/Tcf signaling induces the transcription of axin2, a negative regulator of the signaling pathway. Mol Cell Biol 22: 1172-1183, 2002

49. Chen HY, Lang YD, Lin HN, Liu YR, Liao CC, Nana AW, Yen Y and Chen RH: MiR-103/107 prolong wnt/ $\beta$-catenin signaling and colorectal cancer stemness by targeting axin2. Sci Rep 9: 9687, 2019.

50. Liu C, Kato Y, Zhang Z, Do VM, Yankner BA and He X Beta-trcp couples beta-catenin phosphorylation-degradation and regulates xenopus axis formation. Proc Natl Acad Sci USA 96 6273-6278, 1999.

51. He TC, Sparks AB, Rago C, Hermeking H, Zawel L, da Costa LT, Morin PJ, Vogelstein B and Kinzler KW: Identifcation of c-myc as a target of the APC pathway. Science 281: 1509-1512, 1998.

52. Jubb AM, Chalasani S, Frantz GD, Smits R, Grabsch HI, Kavi V, Maughan NJ, Hillan KJ, Quirke P and Koeppen H: Achaete-Scute like 2 (ascl2) is a target of wnt signalling and is upregulated in intestinal neoplasia. Oncogene 25: 3445-3457, 2006
53. Lustig B, Jerchow B, Sachs M, Weiler S, Pietsch T, Karsten U, van de Wetering M, Clevers H, Schlag PM, Birchmeier W and Behrens J: Negative feedback loop of wnt signaling through upregulation of conductin/axin2 in colorectal and liver tumors. Mol Cell Biol 22: 1184-1193, 2002.

54. Wu ZQ, Brabletz T, Fearon E, Willis AL, Hu CY, Li XY and Weiss SJ: Canonical wnt suppressor, axin2, promotes colon carcinoma oncogenic activity. Proc Natl Acad Sci USA 109: 11312-11317, 2012

55. Sokolosky ML, Stadelman KM, Chappell WH, Abrams SL, Martelli AM, Stivala F, Libra M, Nicoletti F, Drobot LB, Franklin RA, et al: Involvement of akt-1 and mTOR in sensitivity of breast cancer to targeted therapy. Oncotarget 2: 538-550,2011.

56. Zhao G, Han X, Zheng S, Li Z, Sha Y, Ni J, Sun Z, Qiao S and Song Z: Curcumin induces autophagy, inhibits proliferation and invasion by downregulating AKT/mTOR signaling pathway in human melanoma cells. Oncol Rep 35: 1065-1074, 2016.

57. Zhu FQ, Chen MJ, Zhu M, Zhao RS, Qiu W, Xu X, Liu H, Zhao HW, Yu RJ, Wu XF, et al: Curcumin suppresses epithelial-mesenchymal transition of renal tubular epithelial cells through the inhibition of Akt/mTOR pathway. Biol Pharm Bull 40: 17-24, 2017.

58. Yun JH, Park YG, Lee KM, Kim J and Nho CW: Curcumin induces apoptotic cell death via oct4 inhibition and GSK-3 $\beta$ activation in NCCIT cells. Mol Nutr Food Res 59: 1053-1062, 2015.

59. Marin YE, Wall BA, Wang S, Namkoong J, Martino JJ, Suh J, Lee HJ, Rabson AB, Yang CS, Chen S and Ryu JH: Curcumin downregulates the constitutive activity of NF- $\mathrm{NB}$ and induces apoptosis in novel mouse melanoma cells. Melanoma Res 17: 274-283, 2007

60. Marjaneh RM, Rahmani F, Hassanian SM, Rezaei N, Hashemzehi M, Bahrami A, Ariakia F, Fiuji H, Sahebkar A, Avan A and Khazaei M: Phytosomal curcumin inhibits tumor growth in colitis-associated colorectal cancer. J Cell Physiol 233: 6785-6798, 2018.

61. Aoki H, Takada Y, Kondo S, Sawaya R, Aggarwal BB and Kondo Y: Evidence that curcumin suppresses the growth of malignant gliomas in vitro and in vivo through induction of autophagy: Role of Akt and extracellular signal-regulated kinase signaling pathways. Mol Pharmacol 72: 29-39, 2007.

(i) (9) This work is licensed under a Creative Commons CY No NO Attribution-NonCommercial-NoDerivatives 4.0 International (CC BY-NC-ND 4.0) License. 